\title{
Downregulation of long non-coding RNA UCA1 enhances the radiosensitivity and inhibits migration via suppression of epithelial-mesenchymal transition in colorectal cancer cells
}

\author{
XIAODONG YANG ${ }^{1 *}$, WEI LIU ${ }^{1,5^{*}}$, XIAOHUI XU ${ }^{1,2}$, JUNJIA ZHU $^{1}$, YONG WU $^{1}$, KUI ZHAO $^{1}$, \\ SONGBIN HE ${ }^{6}$, MING $\mathrm{LI}^{3,4}$, YONGYOU WU ${ }^{1}$, SHUYU ZHANG ${ }^{3,4}$, JIANPING CAO ${ }^{3,4}$, \\ ZHENYU YE ${ }^{1}$ and CHUNGEN XING ${ }^{1}$
}

\author{
${ }^{1}$ Department of General Surgery, The Second Affiliated Hospital of Soochow University, Suzhou, Jiangsu 215004; \\ ${ }^{2}$ Department of General Surgery, The First People's Hospital of Taicang City, Taicang Affiliated Hospital of Soochow University, \\ Taicang, Jiangsu 215400; ${ }^{3}$ School of Radiation Medicine and Protection, Medical College of Soochow University; \\ ${ }^{4}$ Collaborative Innovation Center of Radiation Medicine of Jiangsu Higher Education Institutions, Suzhou, Jiangsu 215123; \\ ${ }^{5}$ Department of General Surgery, The Laiwu City People's Hospital, Laiwu, Shandong 271100; \\ ${ }^{6}$ Department of General Surgery, The First Affiliated Hospital of Soochow University, Suzhou, Jiangsu 215004, P.R. China
}

Received August 30, 2017; Accepted May 31, 2018

DOI: $10.3892 /$ or.2018.6573

\begin{abstract}
Colorectal cancer (CRC) is the third most commonly diagnosed cancer and common cause of cancer-related deaths. Radiotherapy has become a routine treatment for CRC. However, radioresistance affects therapeutic efficacy. Long non-coding RNA urothelial carcinoma associated 1 (UCA1) has been demonstrated to be overexpressed in several tumors and predicts a poor prognosis. In the present study, we revealed that IncRNA-UCA1 was overexpressed in colorectal cancer tissue and colon cancer cells when compared to normal tissue and cells. Quantitative real-time PCR revealed that the expression of UCA1 was significantly higher in CRC tissues after chemoradiotherapy. Downregulation of UCA1 enhanced the radiosensitivity of CCL244 cells via inhibition of the colony formation, proliferation and promotion of radiation-induced apoptosis and G2/M arrest. Moreover, downregulation of UCA1 suppressed the epithelial-mesenchymal transition (EMT) in CCL244 cells.
\end{abstract}

Correspondence to: Professor Chungen Xing or Professor Zhenyu Ye, Department of General Surgery, The Second Affiliated Hospital of Soochow University, 1055 Sanxiang Road, Suzhou, Jiangsu 215004, P.R. China

E-mail: xingcg@126.com

E-mail: yezhenyu2006@sina.com

${ }^{*}$ Contributed equally

Key words: UCA1, radiosensitivity, migration, EMT, colorectal cancer, CCL244

\section{Introduction}

Colorectal cancer (CRC) is the third most malignant tumor and common cause of death in both men and women worldwidely (1). Radiotherapy (RT), chemotherapy and surgical resection are the conventional treatment options of colorectal cancer (2). In recent years, radiotherapy has generally become a routine treatment for colorectal cancer (3). Compared to standardized total mesorectal excision (TME) alone, preoperative radiotherapy can produce a higher survival rate (4). However, radiation resistance can lead to tumor recurrence and poor prognosis. Consequently, overcoming tumor radioresistance and promoting radiosensitivity are of vital importance for the treatment and prognosis of CRC.

Non-coding RNAs (ncRNAs) are functional RNA molecules that cannot be translated into proteins, compared to protein-coding RNAs (5). These ncRNAs are divided into short ncRNAs and long non-coding RNAs (IncRNAs) according to their length (6). As a member of ncRNA family, IncRNAs are defined as an RNA transcript of more than 200 nucleotides (nt) $(7,8)$. In the last decade, a number of IncRNAs have been revealed to play an important role in the regulation of tumors. Recently, it was revealed that MALAT1 promoted CRC tumor development via its target protein AKAP-9 (9). Upregulation of HOTAIR drove malignancy in gastrointestinal stromal tumors (10). High expression of lncRNA DANCR (anti-differentiation ncRNA) was associated with poor prognosis for both OS and DFS in CRC (11). IncRNA-UCA1 has been demonstrated to play an oncogenic role in breast cancer in part through the suppression of p27 and by influencing cell proliferation, apoptosis and cell cycle distribution of CRC cells $(12,13)$. In addition, UCA1 had been reported in many other cancers such as tongue squamous cell carcinomas, bladder cancer, melanoma and non-small cell lung cancer (14-19). 
Epithelial-mesenchymal transition (EMT) is a process characterized by loss of cell-cell adhesion and gain of migratory traits (20). The EMT process has been reported in many types of cancer such as colorectal cancer $(20,21)$. EMT is controlled by many transcriptional regulators and non-coding RNAs (22). IncRNA H19 modulated EMT by acting as a competing endogenous RNA in CRC (20) knockdown of SPRY4-IT1 and MALAT1 inhibited EMT phenotype in glioma cells and cervical cancer cells $(23,24)$. To date, there is no study concerning the influence of UCA1 on EMT.

Although UCA1 has been revealed to play an important role in tumor regulation, whether it modulated the radiosensitivity of CRC cells was still unknown. In the present study, we aimed to explore the impact of UCA1 silencing on EMT and radiosensitivity of CRC.

\section{Materials and methods}

Collection of clinical samples. CRC tissues and adjacent normal tissues from 32 CRC patients were collected immediately after surgical resection from The Second Affiliated Hospital of Soochow University (Suzhou, China). Fresh colorectal cancer tissues and the paired adjacent normal tissues with a distance of $10 \mathrm{~cm}$ from the border of the tumor tissues were stored at $-80^{\circ} \mathrm{C}$. None of the patients had undergone any treatment before surgical resection. In addition, four pairs of CRC tissues before and after radiotherapy were collected from The Second Affiliated Hospital of Soochow. The present study was conducted in accordance with the Declaration of Helsinki and approved by the Ethics Committee of Soochow University. Signed informed consent was obtained from all participants. The diagnosis of CRC was based on the World Health Organization criteria. The clinical stage of CRC was evaluated based on the TNM classification system. The data included age, sex, tumor size, stage, differentiation levels, invasion level such as lymphatic invasion, perineural invasion and vascular invasion. Tables I and II reveal the clinical characteristics of these patients. In addition, the radiotherapy effect was evaluated according to the WHO standards: CR, tumor completely disappeared; PR, $>50 \%$ tumor shrinkage; $\mathrm{SD}$, not $>50 \%$ tumor shrinkage; PD, tumor volume increased.

Cell culture and treatment. Human CRC-derived cell lines HCT116, CCL244, SW480, LoVo and normal epithelial cells FHC were purchased from the Shanghai Institute of Cell Biology (Shanghai, China) and stored in the laboratory of the School for Radiological and Interdisciplinary Sciences, Soochow University (Suzhou, China). All the cells were cultured in high-glucose Dulbecco's modified Eagle's medium (DMEM; HyClone Laboratories; GE Healthcare, Chicago, IL, USA) supplemented with $10 \%$ fetal bovine serum (FBS; Biological Industries, Kibbutz Beit Haemek, Israel), $100 \mathrm{U} / \mathrm{ml}$ penicillin $\mathrm{G}$ and $100 \mathrm{mg} / \mathrm{ml}$ streptomycin (HyClone Laboratories; GE Healthcare) and maintained at $37^{\circ} \mathrm{C}$ in a humidified atmosphere with $5 \% \mathrm{CO}_{2}$. Cells were exposed to a single dose of X-ray irradiation from a linear accelerator (Rad Source Technologies, Inc., Suwanee, GA, USA) at a dose rate of $1.15 \mathrm{~Gy} / \mathrm{min}$ or sham-irradiated.
Table I. Clinical characteristics of the CRC patients.

\begin{tabular}{|c|c|}
\hline Clinical parameters & Numbers \\
\hline Cases & 32 \\
\hline \multicolumn{2}{|l|}{ Age (years) } \\
\hline$<65$ & 17 \\
\hline$\geq 65$ & 15 \\
\hline \multicolumn{2}{|l|}{ Tumor size $(\mathrm{cm})$} \\
\hline Small size $(<5)$ & 14 \\
\hline Large size $(\geq 5)$ & 18 \\
\hline \multicolumn{2}{|l|}{ Sex } \\
\hline Male & 16 \\
\hline Female & 16 \\
\hline \multicolumn{2}{|l|}{ Invasion levels } \\
\hline Mucosa & 2 \\
\hline Submucosa & 3 \\
\hline Muscle & 6 \\
\hline Serosa & 21 \\
\hline \multicolumn{2}{|l|}{ TNM stage } \\
\hline Stage $1-2$ & 10 \\
\hline Stage 3-4 & 22 \\
\hline \multicolumn{2}{|c|}{ Lymph node metastasis } \\
\hline Positive & 15 \\
\hline Negative & 17 \\
\hline \multicolumn{2}{|l|}{ Grade of tumors } \\
\hline Low grade & 8 \\
\hline Intermediate grade & 22 \\
\hline High grade & 2 \\
\hline \multicolumn{2}{|l|}{ Vascular invasion } \\
\hline Positive & 12 \\
\hline Negative & 20 \\
\hline \multicolumn{2}{|l|}{ Perineural invasion } \\
\hline Positive & 11 \\
\hline Negative & 21 \\
\hline
\end{tabular}

Constructionandtransfection of siRNAs. The siRNA sequences silencing human UCA1 (si-UCA1) were designed and synthesized by Shanghai GenePharma, Co., Ltd. (Shanghai, China). The negative control siRNA was also provided by Shanghai GenePharma Co., Ltd. The siRNA sequences are presented in Table III. CCL244 cells were transiently transfected using Lipofectamine 2000 (Invitrogen; Thermo Fisher Scientific, Inc., Waltham, MA, USA). After transfection for $4 \mathrm{~h}$, the serum-free medium was replaced by a medium containing $10 \%$ FBS. After transfection for $48 \mathrm{~h}$, the cells were harvested for further experiments. Quantitative real-time PCR was used to determine the efficiency of transfection.

$R N A$ extraction and real-time $R T-P C R$. Total RNA was extracted from cells and tissues using TRIzol reagent (Invitrogen; Thermo Fisher Scientific, Inc.). The reverse transcription of mRNAs was performed using a Reverse 
Table II. Clinical characteristics of the CRC patients who received radiotherapy.

\begin{tabular}{llcc}
\hline Sample number & \multicolumn{1}{c}{ Treatment protocols } & Radiotherapy effect & Distant metastasis \\
\hline 1 & 6MvX-ray IMRT DT5000cGy/200cGy/25f & PR & NO \\
& mFOLFOX6 & PR & NO \\
& 6MvX-ray 3DCRT Dt4500cGy/180Gy/25f & & NO \\
FOLFOX & SD & NO \\
& 6MvX-ray IMRT DT5000cGy/200cGy/25f & SD & \\
XELOX & 6 MvX-ray 3DCRT Dt4500cGy/180Gy/25f & & XELOX \\
\hline
\end{tabular}

$\mathrm{CR}$, tumor completely disappeared; $\mathrm{PR},>50 \%$ tumor shrinkage; $\mathrm{SD}$, not $>50 \%$ tumor shrinkage; $\mathrm{PD}$, tumor volume increased.

Table III. Target sequences of UCA1 siRNAs and negative control (NC) siRNA.

\begin{tabular}{|c|c|}
\hline siRNAs & Target sequences \\
\hline si-UCA1-1 sense & 5'-GAGCCGAUCAGACAAACAATT-3' \\
\hline si-UCA1-1 antisense & 5'-UUGUUUGUCUGAUCGGCUCTT-3' \\
\hline si-UCA1-2 sense & 5'-GGGCUUGGGACAUUUCACUTT-3' \\
\hline si-UCA1-2 antisense & 5'-AGUGAAAUGUCCCAAGCCCTT-3' \\
\hline si-UCA1-3 sense & 5'-GGGAAUACUAUUCGUAUGATT-3' \\
\hline si-UCA1-3 antisense & 5'-UCAUACGAAUAGUAUUCCCTT-3' \\
\hline NC sense & 5'-UUCUCCGAACGUGUCACGUTT-3' \\
\hline $\mathrm{NC}$ antisense & 5'-ACGUGACACGUUCGGAGAATT-3' \\
\hline
\end{tabular}

Table IV. Primer sequences for qRT-PCR analysis.

\begin{tabular}{llc}
\hline Gene & Forward sequence & Reverse sequence \\
\hline UCA1 & 5'-GCCCCTTGGACCATCACA-3' & 5'-GACGGCAGTTGGTGTGCTAT-3' \\
GAPDH & 5'-CATGAGAAGTATGACAACAGCCT-3' & 5'-AGTCCTTCCACGATACCAAAGT-3' \\
\hline
\end{tabular}

Transcription kit (Roche, Basel, Switzerland). The real-time PCR assay was carried out with a SYBR-Green kit (Tiangen Biotech Co., Beijing, China) on an ABI 7500 system (Applied Biosystems, Foster City, CA, USA). The thermocycling conditions were as follows: Initial denaturation: At $94^{\circ} \mathrm{C}$ for $3 \mathrm{~min} 30$ cycles: At $94^{\circ} \mathrm{C}$ for $30 \mathrm{sec}$, at $55^{\circ} \mathrm{C}$ for $30 \mathrm{sec}$, and at $72^{\circ} \mathrm{C}$ for $1 \mathrm{~min}$; final extension: At $72^{\circ} \mathrm{C}$ for $5 \mathrm{~min}$. The GAPDH genes were used for the detection of normalization of each sample. The relative expression of UCA1 was calculated using the $2^{-\Delta \Delta C t}$ method. The primers of UCA1 and GAPDH were designed by Shanghai GenePharma Co., Ltd. The primer sequences are presented in Table IV.

Cell proliferation assays. An MTT assay was used to examine cell proliferation. After transfection, the cells were seeded in a 96-well plate at 2,000 cells/well and cultured in normal medium. The cells were subjected to 8-Gy irradiation after $24 \mathrm{~h}$. After 48 and $72 \mathrm{~h}$, the cells were incubated in $0.5 \mathrm{mg} / \mathrm{ml}$ MTT at $37^{\circ} \mathrm{C}$ for $4 \mathrm{~h}$ and lysed in dimethyl sulfoxide (DMSO) at room temperature for $10 \mathrm{~min}$. Then, viability was assessed by obtaining the optical density (OD) values using a microplate reader (Bio-Rad Laboratories, Inc., Hercules, CA, USA) at a wavelength of $490 \mathrm{~nm}$.

Colony-formation assay. After transfection, the cells were inoculated into 6-well plates at 300, 500, 3,000 and 8,000 cells/well and exposed to X-rays with different irradiation doses of 0,2 , 4, 6 and 8 Gy after 24 h. Following 14 days of incubation, the colonies were fixed with $4 \%$ paraformaldehyde and stained with Giemsa. Colonies with a minimum of 50 cells were counted. The radiation sensitivity enhancement ratio (SER) was measured according to the multi-target single hit model. 
Cell apoptosis assays. Apoptosis was assessed using Annexin V/propidium iodide (PI) double-staining following the manufacturer's instructions (BD Biosciences, San Jose, CA, USA). After transfection with siRNA and NC-siRNA for $24 \mathrm{~h}$, the cells were treated with $8 \mathrm{~Gy}$ X-ray irradiation. Cells were washed twice with cold PBS and resuspended in $1 \mathrm{X}$ binding buffer at a concentration of $1 \times 10^{6}$ cells $/ \mathrm{ml}$. Then, $100 \mu \mathrm{l}$ of the solution ( $1 \times 10^{5}$ cells) was transferred into a $2-\mathrm{ml}$ culture tube. Next, the cells were incubated for $15 \mathrm{~min}$ in the dark following the addition of $5 \mu \mathrm{l}$ FITC-Annexin $\mathrm{V}$ and $5 \mu \mathrm{l}$ of PI. Subsequently, $400 \mu \mathrm{l}$ of $1 \mathrm{X}$ binding buffer was added into each tube. Flow cytometric analysis was performed with the BD FACSDiva ${ }^{\mathrm{TM}}$ software (BD Bioscienes, San Jose, CA, USA) within $1 \mathrm{~h}$.

Cell cycle distribution analysis. After transfection, the cells were subjected to 6-Gy irradiation. Twenty-four hours later, the cells were harvested by trypsin digestion, pelleted by centrifugation, washed with ice-cold PBS, and then fixed with $75 \%$ cold ethanol overnight. The staining solution containing PI (50 mg/ml) (Sigma-Aldrich; Merck KGaA, Darmstadt, Germany) and DNA-free RNAs $(20 \mathrm{mg} / \mathrm{ml})$ were added $30 \mathrm{~min}$ before the detection. The fraction of the population in each phase of the cell cycle was determined as a function of the DNA content using a coulter flow cytometer (Beckman Coulter, Inc., Brea, CA, USA).

Cell wound healing assay. IncRNA-UCA1-silenced and negative control cells with or without 6-Gy irradiation were seeded in 6-well plates and incubated overnight. Wounds were created by scratching cell monolayers with a sterile $200-\mu 1$ plastic pipette tip. The cells were further incubated in a hypoxic environment for $24 \mathrm{~h}$ and images were monitored using phase-contrast microscopy (Nikon Corp., Tokyo, Japan). The analysis of the cell migration assay was performed using the ImageJ software (National Institutes of Health, Bethesda, MD, USA).

Protein extraction and western blot analysis. Cells $\left(1 \times 10^{5}\right.$ cells/dish) in 6-well plates were incubated in DMEM containing $10 \%$ FBS to $70 \%$ confluence. The cells were transfected with siRNA for $24 \mathrm{~h}$ and then were sham-irradiated or exposed to 6-Gy X-ray irradiation. The cells were then harvested in lysis buffer with $1 \mathrm{mM}$ phenylmethylsulfonyl fluoride (PMSF). Subsequently, the cells were allowed to swell on ice for $30 \mathrm{~min}$. The homogenates were centrifuged for $15 \mathrm{~min}$ at $12,000 \mathrm{x} \mathrm{g}$ and the supernatant was used as the cytosolic extract. Proteins were separated using $10 \%$ sodium dodecyl sulfate poly-acrylamide gel electrophoresis (SDS-PAGE) and transferred onto polyvinylidene difluoride (PVDF) membranes The membranes were blocked with 5\% non-fat dried milk in TBS containing 1\% Tween-20 (TBST) for $2 \mathrm{~h}$ at room temperature, followed by incubation with the appropriate primary antibodies caspase-3 (cat. no. sc-7272), Bcl-2 (sc-509; both from Santa Cruz Biotechnology, Inc., Santa Cruz, CA), MMP2 (cat. no. ab92536), MMP9 (cat. no. ab76003), ZEB1 (cat. no. ab124512) and vimentin (cat. no. ab137321; all from Abcam, Cambridge, MA, USA) at a 1:1,000 dilution for $2 \mathrm{~h}$, and either horseradish peroxidase-conjugated goat anti-rabbit or anti-mouse antibodies (cat. nos. A0208 and A0216, respectively; both from Beyotime Institute of Biotechnology, Nantong, China) for $1 \mathrm{~h}$. $\beta$-actin (Beyotime Institute of Biotechnology) was used as the loading control. Antibody-bound proteins were detected using an ECL Stable Peroxide solution (PointBio, Shanghai, China). All protein bands were visualized using a FluroChem MI imaging system (Alpha Innotech, Santa Clara, CA, USA) at the room temperature.

Statistical analysis. All experiments were performed at least three times $(n=3)$. Data were expressed as the means \pm SEM. Student's t-test was used to analyze the data when only two groups were compared or one-way analysis of variance (ANOVA) when more than two groups were compared. Differences were considered statistically significant when $\mathrm{P}<0$.05. SPSS Statistical software (version 19.0; IBM Corp., Armonk, NY, USA) was utilized for statistical analysis.

\section{Results}

UCA1 levels are upregulated in CRC tissues and cell lines. Thirty-two pairs of human CRC and adjacent normal tissues were collected to investigate the expression level of UCA1 using real-time PCR. As shown in Fig. 1A and C, UCA1 was overexpressed in $\mathrm{CRC}$ tissues compared to paired adjacent normal tissues $(\mathrm{P}<0.001)$. In addition, our results demonstrated that UCA1 was highly expressed in human CRC-derived cell lines HCT116, CCL244, SW480 and LoVo, in contrast with the normal epithelial cells FHC (Fig. 1B). These results indicated that UCA1 was significantly upregulated in CRC tumor tissues and cell lines. CCL244 cells were selected to perform the following experiments since the ascending order of these four CRC cell lines in terms of radiosensitivity was demonstrated to be CCL244, SW480, LoVo and HCT116 (25).

Expression of UCA1 in two CRC cell lines and four clinical samples after irradiation compared to unirradiated cells. CCL244 and HCT116 cells were seeded in 6-well plates and then exposed to 8-Gy X-ray irradiation. After $48 \mathrm{~h}$, total RNA was extracted and then a real-time PCR assay was used to detect the expression of UCA1. As shown in Fig. 2A and B, the expression level was higher in the CCL244 cells with irradiation than the cells without irradiation $(\mathrm{P}=0.01)$. However, there was no statistically significant difference in HCT116 cells $(\mathrm{P}=0.84)$. Similarly, Fig. $2 \mathrm{C}$ indicated that the expression of UCA1 was upregulated in four clinical samples after radiotherapy.

UCA1 regulates the radiosensitivity of CCL-244 cells. The results of Fig. 2 demonstrated that UCA1 was upregulated in CCL244 cells following X-ray irradiation. Thus, we conjectured that UCA1 may be involved in the regulation of radiosensitivity of CRC cells. Three different siRNA vectors were transfected into CCL244 cells and the efficiency of transfection was verified by real-time PCR. siRNA-2 exhibited the highest efficiency (57\%) of transfection compared to the other two siRNAs (66 and 62\%) in Fig. 3A. Thus, siRNA-2 was then used for further experiments. siRNA and NC-siRNA were transfected into CCL244 cells and then the cells were exposed to 8-Gy X-ray irradiation after transfection for 


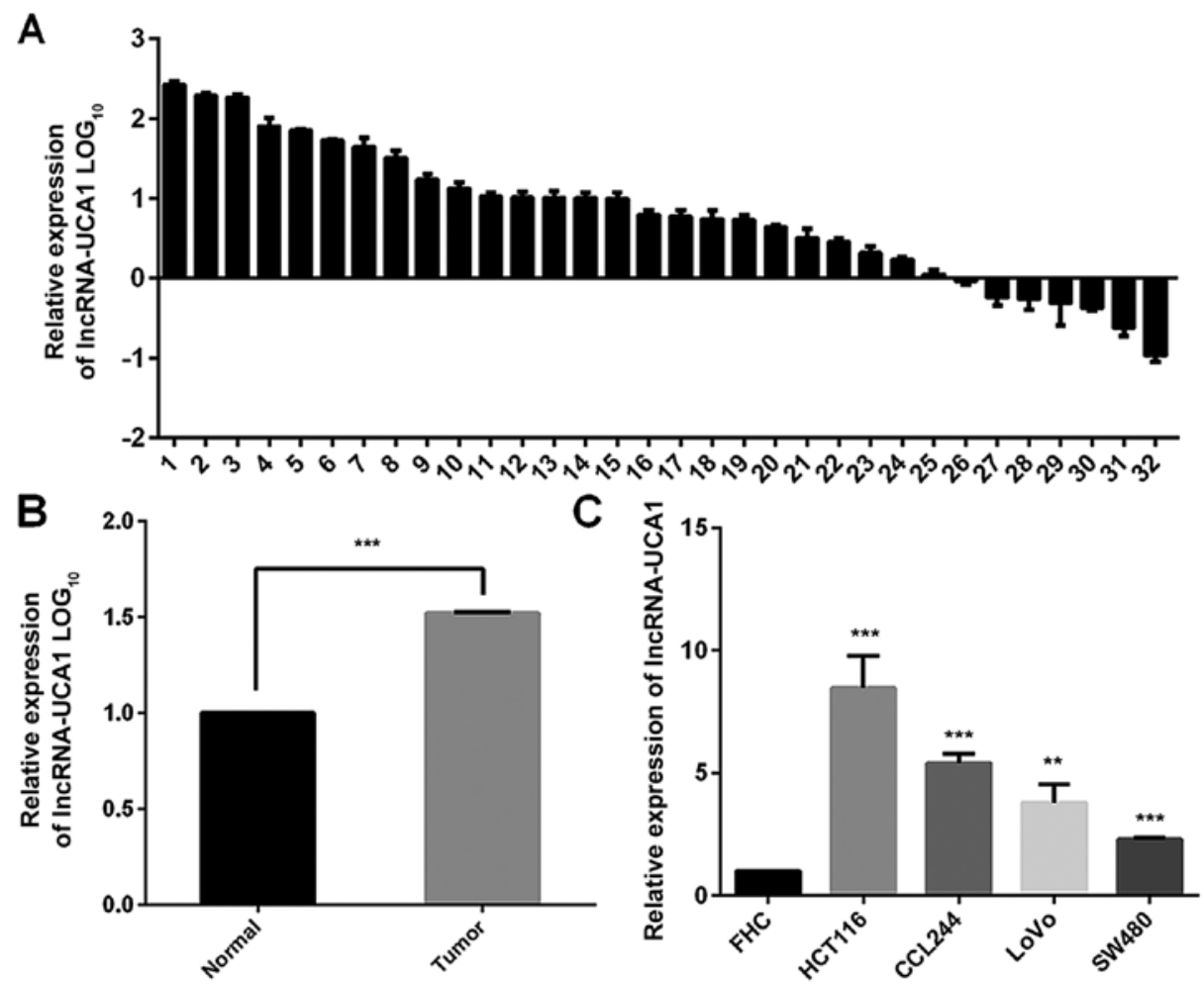

Figure 1. Expression of UCA1 in CRC tissues and cells. (A) Real-time RT-PCR was performed to detect the relative expression of UCA1 in 32 pairs of human CRC cancerous and adjacent non-cancerous tissues. GAPDH was used as an internal control. (B) The mean $2^{-\Delta \Delta C t}$ of UCA1 in the 32 CRC tissues was compared with that in the matched non-cancerous colorectal tissues $\left({ }^{* * *} \mathrm{P}<0.001\right)$. (C) Relative expression of UCA1 $\left(2^{-\Delta \Delta C t}\right)$ in 4 CRC cell lines (HCT116, CCL244, LoVo and SW480) and in one normal colonic mucosal cell line (FHC) $\left({ }^{* *} \mathrm{P}<0.01,{ }^{* * *} \mathrm{P}<0.001\right)$

A

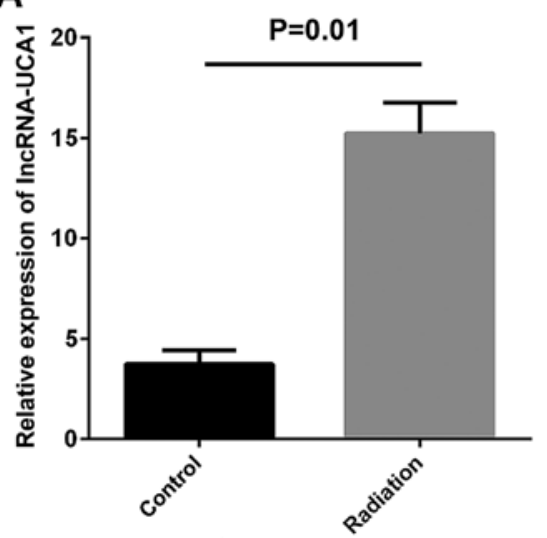

C
B

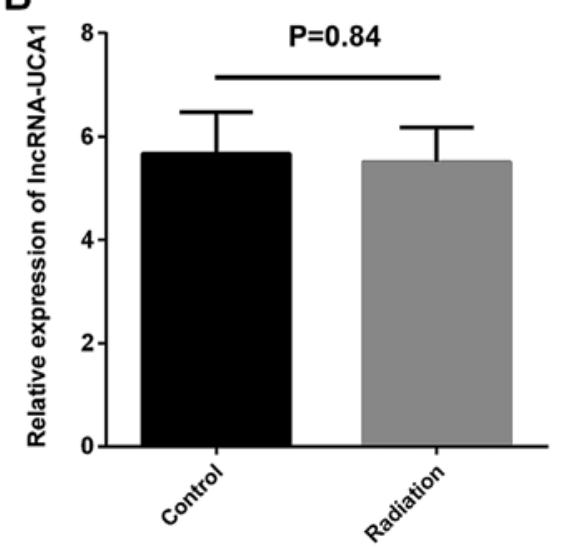

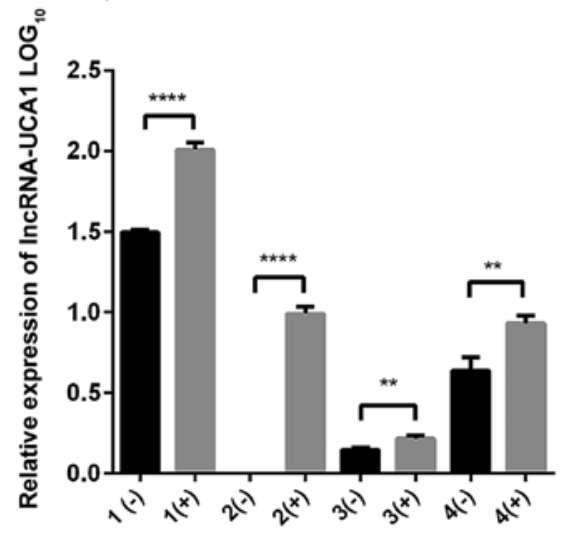

Figure 2. Expression of UCA1 in colorectal cancer cells and tissues before and after X-ray irradiation. (A) The expression of UCA1 in CCL244 cells before and after X-ray irradiation. CCL244 cells after irradiation exhibited higher expression of UCA1 when compared to cells that were not irradiated (P<0.01). (B) The expression of UCA1 in HCT116 cells before and after X-ray irradiation. There was no statistically significant difference in HCT116 cells (P=0.84). (C) The expression of UCA1 was upregulated in four clinical samples after chemoradiotherapy. (-), before chemoradiotherapy; (+), after chemoradiotherapy $\left({ }^{* *} \mathrm{P}<0.01,{ }^{* * * * *} \mathrm{P}<0.0001\right)$. 

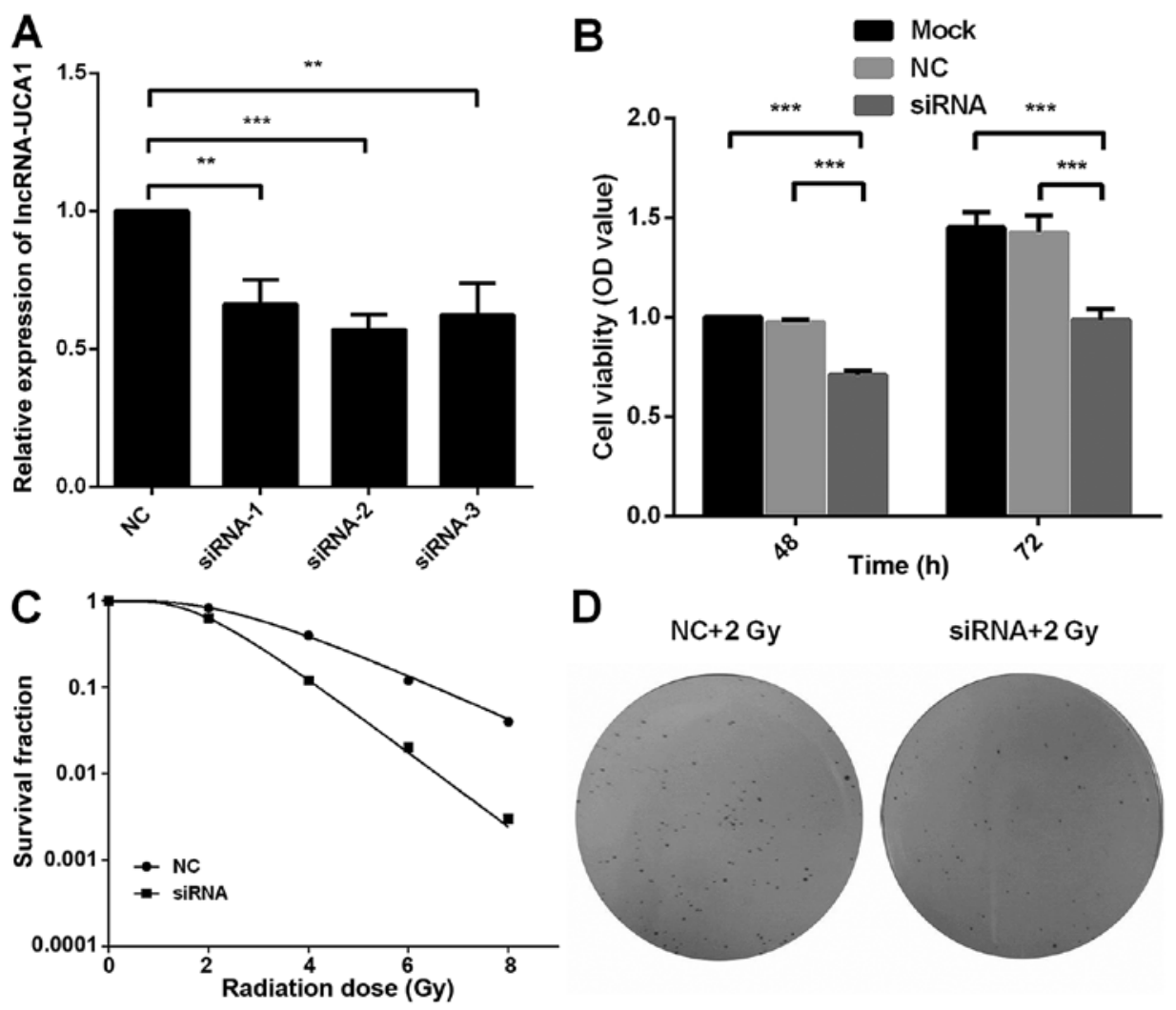

Figure 3. Downregulation of UCA1 influences the radiosensitivity of CCL244 cells. (A) Real-time RT-PCR was used to detect the silencing efficiency of three siRNA sequences ( $\left.{ }^{* *} \mathrm{P}<0.01,{ }^{* * *} \mathrm{P}<0.001\right)$. (B) CCL244 cells were transfected with siRNA and NC. Then the cells were exposed to 8 -Gy irradiation $24 \mathrm{~h}$ later. After 48 and $72 \mathrm{~h}$, an MTT assay were used to detect cell viabilities $\left.{ }^{* * * *} \mathrm{P}<0.001\right)$. (C) Tranfected with siRNA and NC cells were exposed to $2,4,6$ and 8 Gy of X-ray irradiation. Ten days later, the survival curve was obtained by multi-target single hit model. (D) Representative colony images of UCA1-silenced CCL244 cells compared to the negative control exposed to 2 Gy of X-ray irradiation.

$24 \mathrm{~h}$. After 48 and $72 \mathrm{~h}$, MTT and colony-formation assays were performed. The MTT assay demonstrated that the cell viability was reduced after UCA1 downregulation, compared to the mock-transfected cells $(\mathrm{P}<0.001)$ and negative control UCA1 ( $\mathrm{P}<0.001)$ (Fig. 3B). CCL244 cells were transfected with siRNA or NC-siRNA $24 \mathrm{~h}$ prior to irradiation at $0,2,4,6$ and $8 \mathrm{~Gy}$. The multi-target single hit model was used to obtain the dose-survival curves. A dose-dependent radiosensitization on UCA1-silenced cells was also observed with a sensitizing enhancement ratio (SER) of 1.41 (Fig. 3C). Representative colony images of UCA1-silenced CCL244 cells compared to the negative control exposed to $2 \mathrm{~Gy}$ of X-ray irradiation are shown in Fig. 3D. These results demonstrated that downregulation of UCA1 significantly increased the radiosensitivity of CCL244 cells.

Knockdown of UCA1 promotes radiation-induced apoptosis in CCL244 cells and regulates the expression of apoptosis-related proteins. Apoptosis was detected using Annexin V/PI staining with flow cytometry to investigate the role of UCA1 in radiation-induced apoptosis in CCL244 cells. Apoptosis was promoted in the CCL244 cells in the NC+IR group when compared to the NC group [NC $(7.93 \pm 0.20 \%)$ vs. NC+IR (17.60 $\pm 0.69 \%), \mathrm{P}<0.001]$, as shown in Fig. 4A and B. The percentage of apoptosis in the irradiation plus the UCA1-knockdown group was significantly enhanced in contrast with the NC+IR group [siRNA+IR $(33.97 \pm 1.03 \%)$ vs. $\mathrm{NC}+\mathrm{IR}(17.60 \pm 0.69 \%), \mathrm{P}<0.001]$. Furthermore, the expression of apoptosis-related molecules such as Bcl-2 and caspase-3 was evaluated by western blot analysis. As shown in Fig. 4C, the expression of Bcl-2 was downregulated after transfection with siRNA compared to the negative control regardless of irradiation. In contrast with Bcl-2, the expression of caspase- 3 was upregulated. All these results demonstrated that knockdown of UCA1 promoted radiation-induced apoptosis in CCL244 cells.

UCA1 silencing attenuates radiation-induced G2/M arrest. We then studied whether UCA1 had any effects on radiation-induced cell cycle changes. Transfected CCL244 cells were subjected to 6-Gy irradiation. Twenty-four hours later, the cells were harvested and detected by flow cytometry. As shown in Fig. 5, the results revealed that IR caused cell cycle arrest in the $\mathrm{G} 2 / \mathrm{M}$ phase in the NC+IR group when compared to the NC group [NC $(11.77 \pm 1.01 \%)$ vs. NC+IR $(31.81 \pm 1.59 \%)$, $\mathrm{P}<0.001]$. However, the percentage of cells in the G2/M phase was reduced when UCA1 was knocked down after irradiation compared to the NC+IR group [siRNA+IR $(18.87 \pm 1.15 \%)$ vs. NC+IR $(31.81 \pm 1.59 \%) \mathrm{P}<0.01]$. The percentage of radiation-induced $\mathrm{G} 2 / \mathrm{M}$ arrest in the siRNA+IR group was reduced by $12.94 \%$ compared to the NC+IR group. These results indicated that knockdown of UCA1 can reduce the radiation-induced $\mathrm{G} 2 / \mathrm{M}$ arrest.

Knockdown of UCAl inhibits the migration and EMT of CCL244 cells after irradiation. Metastasis is an important factor of poor prognosis in CRC. A wound healing assay was 

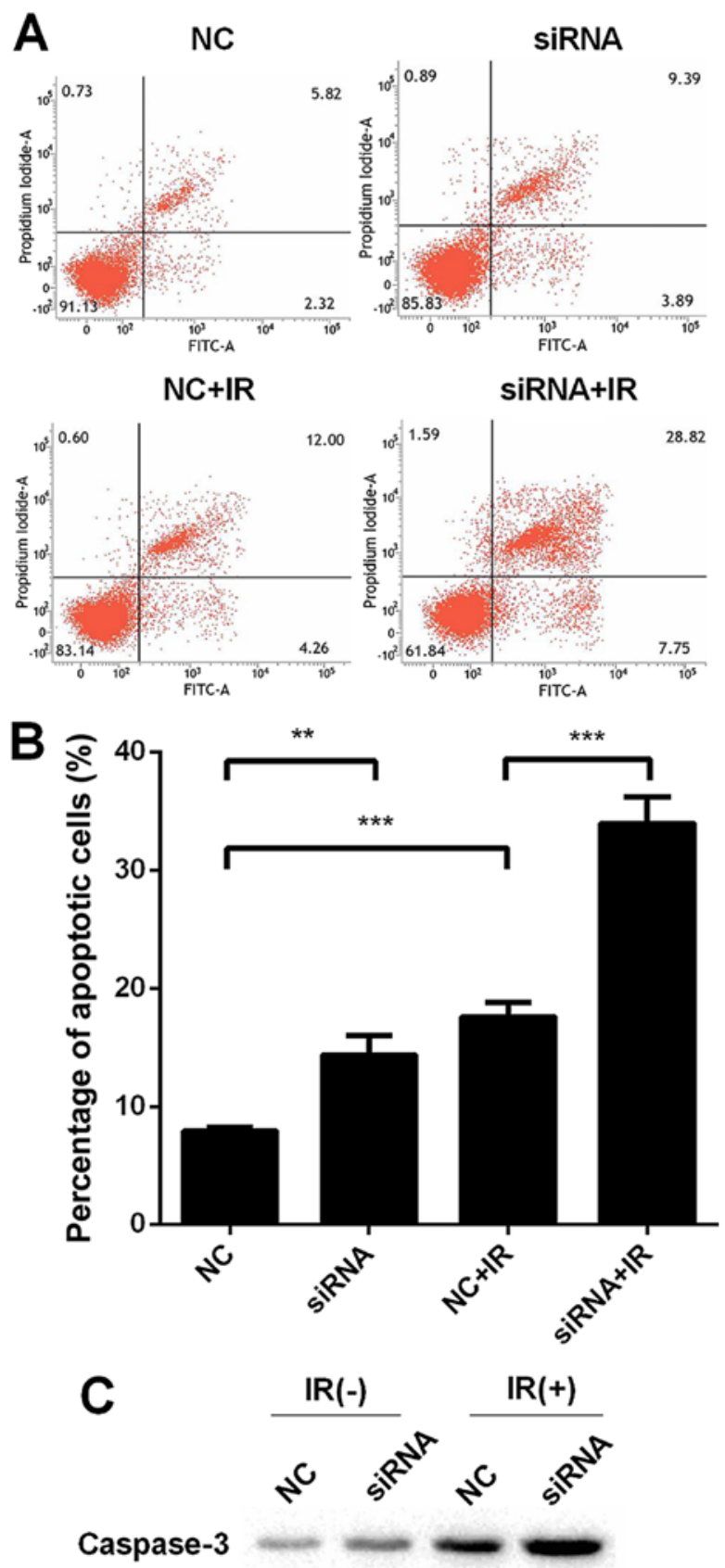

$\mathrm{Bcl}-2$

$\beta$-actin

Figure 4. Downregulation of UCA1 promotes radiation-induced apoptosis of CCL-244 cells. (A) Annexin V/propidium iodide (PI) double-staining was performed to determine the apoptosis of CCL-244 cells transfected with siRNA or NC exposed to $8 \mathrm{~Gy}$ or sham-irradiation. (B) Percentage of apoptotic cells transfected with siRNA or NC exposed to 8 Gy or sham irradiation $\left({ }^{* *} \mathrm{P}<0.01,{ }^{* * *} \mathrm{P}<0.001\right)$. (C) Western blot analysis of the apoptotic marker proteins caspase-3 and Bcl-2 in CCL244 cells transfected with siRNA or NC exposed to 8 Gy or sham-irradiation. GAPDH was used as an internal control.

carried out to investigate the effect of UCA1 on the metastasis of CCL244 cells. Fig. 6A and B revealed that downregulation of UCA1 inhibited the migration of CCL244 cells compared to the negative control CCL244 cells ( 46.38 vs. $59.42 \%, \mathrm{P}<0.05)$. After transfection and exposure to $6 \mathrm{~Gy} \mathrm{X}$-ray irradiation, knockdown of UCA1 (siRNA+IR) significantly inhibited the migration of CCL244 cells compared to cells with X-ray irradiation alone $(\mathrm{NC}+\mathrm{IR})(16.06$ vs. $35.92 \%, \mathrm{P}<0.05)$. As widely known, matrix metalloproteinases (MMPs) are of vital importance in tumor metastasis. ZEB1 promotes EMT by binding to DNA through E-boxes of target gene promoters such as E-cadherin (26). Vimentin is also a biomarker of EMT (27). Western blot analysis revealed that downregulation of UCA1 plus irradiation reduced the expression level of MMP2 and 
A

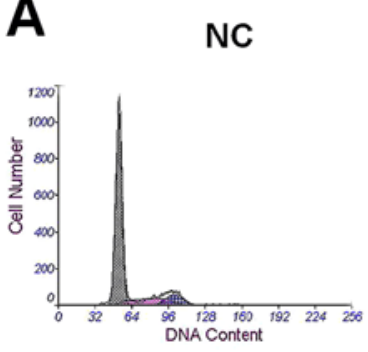

NC+IR

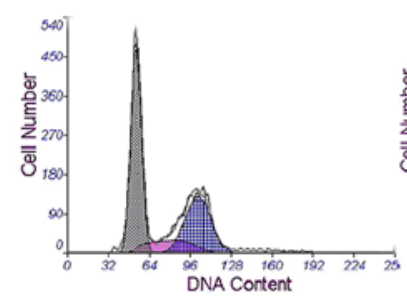

SiRNA

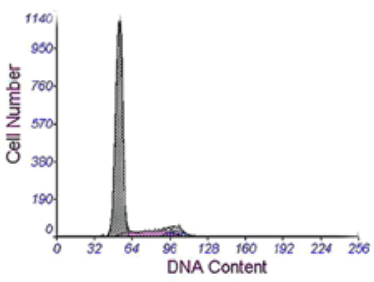

SiRNA+IR

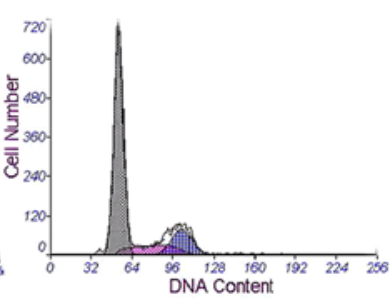

B

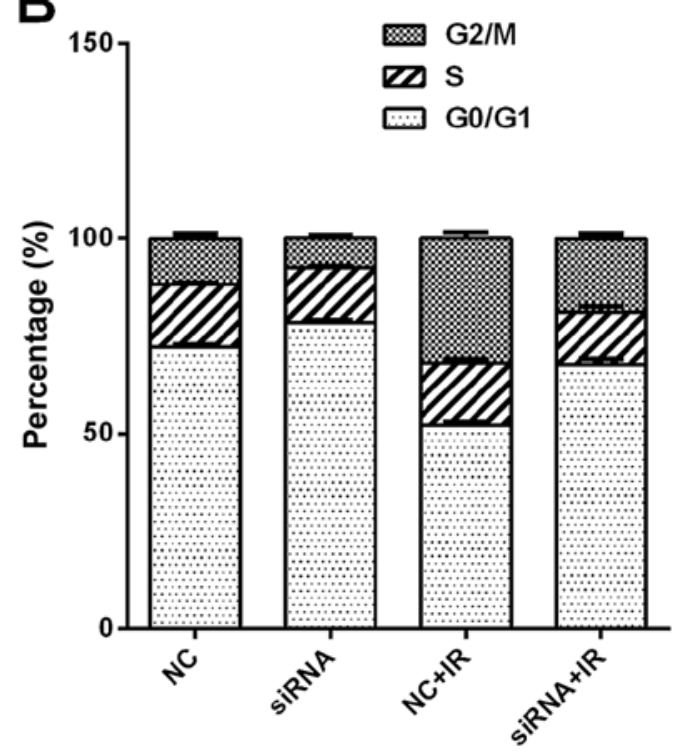

Figure 5. Downregulation of UCA1 attenuates radiation-induced G2/M arrest. (A) Representative images of the cell cycle distribution after UCA1 knockdown and NC cells with irradiation or not. (B) Quantification of the cell cycle distribution after UCA1 knockdown and NC cells with irradiation or not.

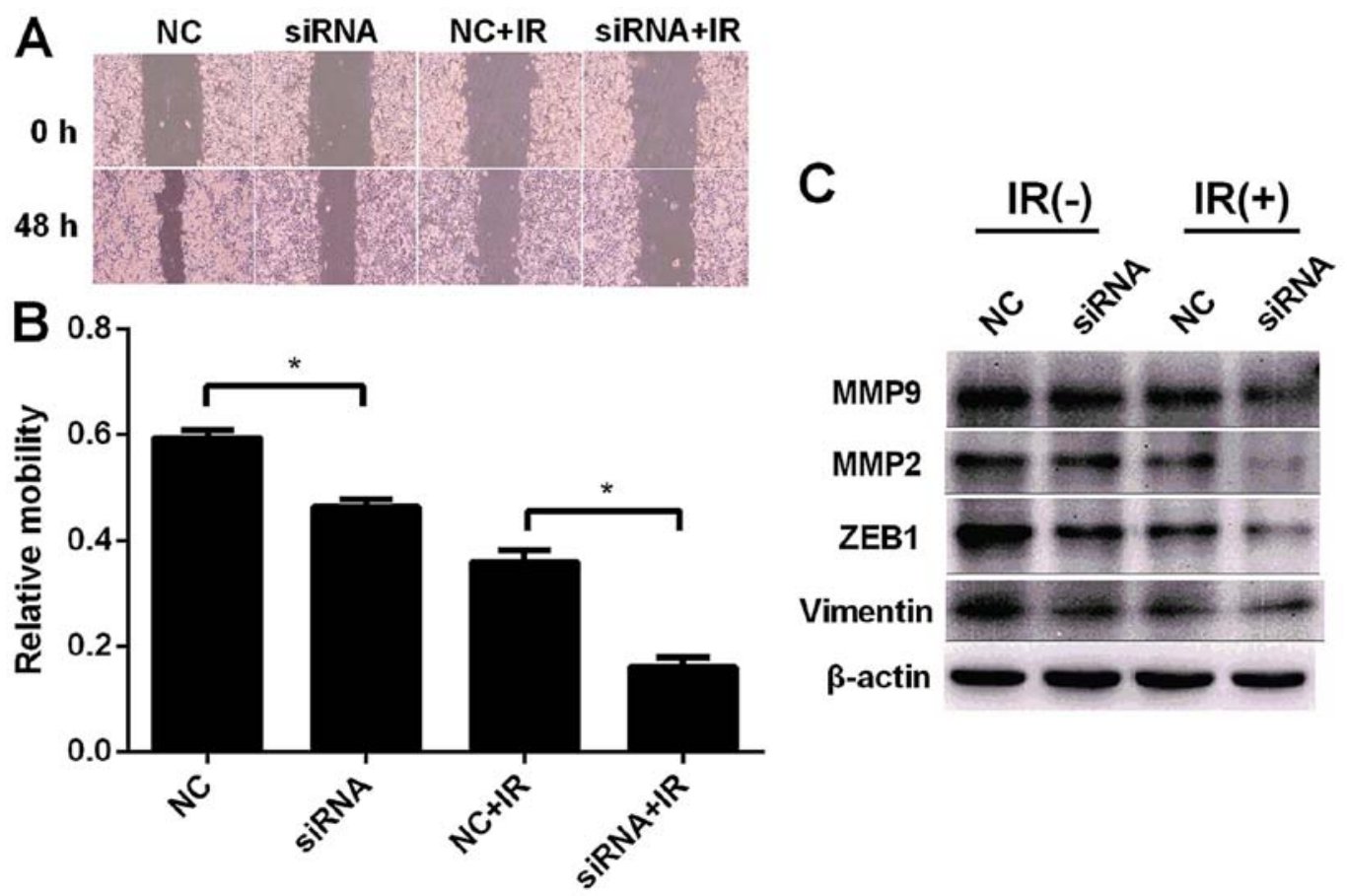

Figure 6. Effect of UCA1 silencing on cell migration and EMT. (A) Representative images of wound healing assays of CCL244 cells after UCA1 silencing plus 6 Gy X-ray irradiation. (B) The relative mobility of UCA1 knockdown and NC cells with irradiation or not ( $\mathrm{P}<0.05)$. (C) The expression level of migration- and EMT-associated proteins MMP2, MMP9, ZEB1 and vimentin.

MMP9. Similar results were obtained in the expression levels of ZEB1 and vimentin (Fig. 6C). These results demonstrated that knockdown of UCA1 inhibited the migration and EMT of CCL244 cells after irradiation.

\section{Discussion}

Radiotherapy is a primary treatment modality for early and locally advanced CRC cancer (28). However, radiation resistance has a greater impact on the treatment effect, which suggests a poor prognosis and high recurrence rate. Therefore, research has begun to focus on how to increase the radiosensitivity of tumor cells. Downregulation of c-myc and MG132 (carbobenzoxyl-leucinyl-leucinyl-leucinal-H) enhanced the radiosensitivity of A549 cells in vivo and in vitro (29). In addition, anti-apoptotic proteins, such as Bcl-2 and Bcl-xL, play an important role in the radioresistance of cancer cells. When acquired radioresistant breast cancer cell 
line MDA-MB-231R was treated with ABT-737, Bcl-2 and $\mathrm{Bcl}-\mathrm{xL}$ were downregulated, radiation-induced apoptosis was increased, restoring the radiosensitivity of the MDA-MB-231R cells (30). The PI3K/Akt/mTOR pathway is an important intracellular signaling pathway involved in the regulation of cell radioresistance $(31,32)$. The PI3K/Akt/mTOR pathway inhibitors BEZ235 and PI103 increase the radiation sensitivity of prostate cancer cells via induction of apoptosis and reduction of autophagy (33). In our previous study, CCL244 was identified as a radioresistant cell line and HCT116 as a radiosensitive cell line as determined through clone formation assay (25). IncRNA UCA1 was identified as a vital lncRNA which was distinctly upregulated in CCL244 cells after irradiation. UCA1 has been established to be involved in many of the biological behaviors of tumor. However, there are no studies concerning UCA1 affecting the radiosensitivity of tumor cells.

In recent years, as long non-coding RNAs have become a hot topic, numerous IncRNAs have been demonstrated to be related with tumor cell radiosensitivity, although UCA1 was not among them. Downregulation of HOTAIR increased the radiosensitivity of cervical cancer when p21 was simultaneously upregulated (34). IncRNA-p21 enhanced the sensitivity of radiotherapy for CRC by targeting the $\beta$-catenin signaling pathway and it may provide a potential target for CRC radiotherapy (35). IncRNA-LIRR1 was able to modulate the radiosensitivity of BEAS-2B cells through the DDR signaling pathways in a p53-dependent manner (36). Downregulation of MALAT1 and upregulation of miR-145 increased the radio-sensitivity in $\mathrm{HR}-\mathrm{HPV}^{+}$cervical cancer (37). In the present study, we identified that UCA1 was upregulated in CCL244 cells after irradiation which indicated that UCA1 may be involved in radioresistance of CRC cells. Since UCA1 was highly expressed in tissues and CCL244 cells, we used small interfering RNA to downregulate UCA1 and investigate the relevance between IncRNA-UCA1 and the radiosensitivity of CRC cells. An MTT assay indicated that silencing of UCA1 significantly decreased the proliferation rate compared to the negative control siRNA when cells were exposed to X-ray irradiation. Colony-formation assay revealed that UCA1-silencing was observed with a sensitizing enhancement ratio (SER) of 1.41 and the colony survival fraction was significantly reduced. All these results indicated that downregulation of UCA1 enhanced the radiosensitivity of CCL244 cells. In addition, UCA1 may be involved in the modulation of chemosensitivity of CRC cells.

Radiation-induced apoptosis was one of modes of radiation-induced cell death (38). IncRNAs were identified to be involved in the modulation of radiation-induced apoptosis. Downregulation of MALAT1 significantly enhanced radiation-induced apoptosis, as the expression of $\mathrm{Bcl}-2$ was decreased and that of caspase-3 was increased (39). It was demonstrated that silencing of HOTAIR increased the radiation-induced apoptosis in CRC cells (40). In the present study, we examined the apoptosis of CCL244 cells after transfection and exposure to X-ray irradiation in order to confirm that UCA1 was involved in regulating the radiosensitivity of CCL244 cells. It was revealed that the downregulation of UCA1 resulted in a higher percentage of radiation-induced apoptosis than the negative control. Moreover, downregulation of UCA1 reduced the expression of Bcl-2 and improved the expression level of caspase-3. All of the aforementioned results demonstrated that downregulation of UCA1 enhanced the radiosensitivity via the promotion of radiation-induced apoptosis.

Cell cycle regulation may be the most important determinant of ionizing radiation sensitivity (41). It has been universally acknowledged that irradiation induces DNA double-strand breaks (DSBs) resulting in G2 arrest and then DNA DSB repair occurrs. The G2 arrest in tumor cells provides time for the repair processes to operate which are critical for ensuring cell survival after DNA damage (41). It was suggested that the combination of BI-69A11 and celecoxib impaired IR-induced DSB repair, attenuated the G2/M cell cycle and then enhanced the radiosensitivity of CRC cancer cells (42). In the present study, CCL244 cells with irradiation revealed prolonged G2/M phase arrest. However, downregulation of UCA1 attenuated the radiation-induced arrest of $\mathrm{G} 2 / \mathrm{M}$ cell cycle. These findings indicated that silencing of UCA1 enhanced the radiosensitivity of CRC by impairing G2/M arrest.

In the last decade, EMT has been widely recognized to play a vital role in the promotion of carcinoma metastasis. IncRNAs have been reported to be involved in the process of EMT. Silencing of HOTAIR prevented the EMT process stimulated by TGF- $\beta 1$ in CRC and breast cancer (43). EMT-associated proteins (ZEB1, ZEB2, Snail, E-cadherin, MMP2, MMP9 and vimentin) have been studied in the EMT process (27). In the present study, we found that downregulation of UCA1 plus irradiation reduced the expression levels of MMP2, MMP9, ZEB1 and vimentin. These results indicated that silencing of UCA1 significantly inhibited EMT in CCL244 cells.

In summary, the present study demonstrated that UCA1 was highly expressed in CRC cells and that downregulation of UCA1 enhanced the radiosensitivity and suppressed EMT of CCL244 cells. All these results demonstrated that IncRNA-UCA1 may be a novel therapeutic target for CRC in radiotherapy.

\section{Acknowledgements}

The authors thank Shuyu Zhang, Ming Li and Jianping Cao for their technical support.

\section{Funding}

The present study was partially supported by the National Natural Science Foundation of China (grant nos. 81672970, 81301933, 81472917 and 81572345), the Natural Science Foundation of Jiangsu Province (no. BK20160338), the projects of Suzhou Technology Bureau (nos. SZS201618, SYS201552 and SYSD2015034), the Focus of Clinical Disease Treatment Technology Special Funds of Suzhou City (LCZX201505) and the Second Affiliated Hospital of Soochow University Preponderant Clinic Discipline Group Project Funding.

\section{Availability of data and materials}

The datasets used during the present study are available from the corresponding author upon reasonable request. 


\section{Authors' contributions}

CX and ZY conceived and designed the study. WL and XY performed the experiments and wrote the paper. WL, XY, XX, JZ, YongW, KZ and SH were involved in the conception of the study. SZ, ML, YongyouW and JC provided technical support. All authors read and approved the manuscript and agree to be accountable for all aspects of the research in ensuring that the accuracy or integ-rity of any part of the work are appropriately investigated and resolved.

\section{Ethics approval and consent to participate}

All experimental protocols were approved by the Institutional Review Board of the Second Affiliated Hospital of Soochow University, Suzhou, Jiangsu 215004.

\section{Consent for publication}

Not applicable.

\section{Competing interests}

The authors state that they have no competing interests.

\section{References}

1. El-Shami K, Oeffinger KC, Erb NL, Willis A, Bretsch JK, Pratt-Chapman ML, Cannady RS, Wong SL, Rose J, Barbour AL, et al: American cancer society colorectal cancer survivorship care guidelines. CA Cancer J Clin 65: 428-455, 2015.

2. Jonker FH, Tanis PJ, Coene PP and van der Harst E; Dutch Surgical Colorectal Audit Group: Impact of neoadjuvant radiotherapy on complications after hartmann procedure for rectal cancer. Dis Colon Rectum 58: 931-937, 2015.

3. van Leersum NJ, Snijders HS, Wouters MW, Henneman D, Marijnen CA, Rutten HR, Tollenaar RA and Tanis PJ; Dutch Surgical Colorectal Cancer Audit Group: Evaluating national practice of preoperative radiotherapy for rectal cancer based on clinical auditing. Eur J Surg Oncol 39: 1000-1006, 2013.

4. Elferink MA, van Steenbergen LN, Krijnen P, Lemmens VE, Rutten HJ, Marijnen CA, Nagtegaal ID, Karim-Kos HE, de Vries E and Siesling S; Working Group Output of the Netherlands Cancer Registry: Marked improvements in survival of patients with rectal cancer in the Netherlands following changes in therapy, 1989-2006. Eur J Cancer 46: 1421-1429, 2010

5. Sun QL, Zhao CP, Wang TY, Hao XB, Wang XY, Zhang X and $\mathrm{Li}$ YC: Expression profile analysis of long non-coding RNA associated with vincristine resistance in colon cancer cells by next-generation sequencing. Gene 572: 79-86, 2015.

6. Guan D, Zhang W, Zhang W, Liu GH and Belmonte JC: Switching cell fate, ncRNAs coming to play. Cell Death Dis 4: e464, 2013.

7. Han D, Wang M, Ma N, Xu Y, Jiang Y and Gao X: Long noncoding RNAs: Novel players in colorectal cancer. Cancer Lett 361: 13-21, 2015.

8. Rupaimoole R, Lee J, Haemmerle M, Ling H, Previs RA, Pradeep S, Wu SY, Ivan C, Ferracin M, Dennison JB, et al: Long noncoding RNA ceruloplasmin promotes cancer growth by altering glycolysis. Cell Rep 13: 2395-2402, 2015.

9. Yang MH, Hu ZY, Xu C, Xie LY, Wang XY, Chen SY and Li ZG: MALAT1 promotes colorectal cancer cell proliferation/migration/invasion via PRKA kinase anchor protein 9. Biochim Biophys Acta 1852: 166-174, 2015.

10. Niinuma T, Suzuki H, Nojima $M$, Nosho $K$, Yamamoto $H$, Takamaru H, Yamamoto E, Maruyama R, Nobuoka T, Miyazaki Y, et al: Upregulation of miR-196a and HOTAIR drive malignant character in gastrointestinal stromal tumors. Cancer Res 72: 1126-1136, 2012.
11. Liu Y, Zhang M, Liang L, Li J and Chen YX: Over-expression of lncRNA DANCR is associated with advanced tumor progression and poor prognosis in patients with colorectal cancer. Int J Clin Exp Pathol 8: 11480-11484, 2015.

12. Huang J, Zhou N, Watabe K, Lu Z, Wu F, Xu M and Mo YY: Long non-coding RNA UCA1 promotes breast tumor growth by suppression of p27 (Kip1). Cell Death Dis 5: e1008, 2014.

13. Han Y, Yang YN, Yuan HH, Zhang TT, Sui H, Wei XL, Liu L, Huang P, Zhang WJ and Bai YX: UCA1, a long non-coding RNA up-regulated in colorectal cancer influences cell proliferation, apoptosis and cell cycle distribution. Pathology 46: 396-401, 2014.

14. Fang Z, Wu L, Wang L, Yang Y, Meng Y and Yang H: Increased expression of the long non-coding RNA UCA1 in tongue squamous cell carcinomas: A possible correlation with cancer metastasis. Oral Surg Oral Med Oral Pathol Oral Radiol 117: 89-95, 2014.

15. Wu W, Zhang S, Li X, Xue M, Cao S and Chen W: Ets-2 regulates cell apoptosis via the Akt pathway, through the regulation of urothelial cancer associated 1, a long non-coding RNA, in bladder cancer cells. PLoS One 8: e73920, 2013.

16. Yang C, Li X, Wang Y, Zhao L and Chen W: Long non-coding RNA UCA1 regulated cell cycle distribution via CREB through PI3-K dependent pathway in bladder carcinoma cells. Gene 496: 8-16, 2012.

17. Fan Y, Shen B, Tan M, Mu X, Qin Y, Zhang F and Liu Y: Long non-coding RNA UCA1 increases chemoresistance of bladder cancer cells by regulating Wnt signaling. FEBS J 281: 1750-1758, 2014.

18. Tian Y, Zhang X, Hao Y, Fang Z and He Y: Potential roles of abnormally expressed long noncoding RNA UCA1 and Malat-1 in metastasis of melanoma. Melanoma Res 24: 335-341, 2014.

19. Wang HM, Lu JH, Chen WY and Gu AQ: Upregulated lncRNA-UCA1 contributes to progression of lung cancer and is closely related to clinical diagnosis as a predictive biomarker in plasma. Int J Clin Exp Med 8: 11824-11830, 2015.

20. Liang WC, Fu WM, Wong CW, Wang Y, Wang WM, Hu GX, Zhang L, Xiao LJ, Wan DC, Zhang JF, et al: The lncRNA H19 promotes epithelial to mesenchymal transition by functioning as miRNA sponges in colorectal cancer. Oncotarget 6: 22513-22525, 2015.

21. Zhu W, Cai MY, Tong ZT, Dong SS, Mai SJ, Liao YJ, Bian XW, Lin MC, Kung HF, Zeng YX, et al: Overexpression of EIF5A2 promotes colorectal carcinoma cell aggressiveness by upregulating MTA1 through c-myc to induce epithelial-mesenchymaltransition. Gut 61: 562-575, 2012.

22. Cao H, Xu E, Liu H, Wan L and Lai M: Epithelial-mesenchymal transition in colorectal cancer metastasis: A system review. Pathol Res Pract 211: 557-569, 2015.

23. Liu H, Lv Z and Guo E: Knockdown of long noncoding RNA SPRY4-IT1 suppresses glioma cell proliferation, metastasis and epithelial-mesenchymal transition. Int J Clin Exp Pathol 8: 9140-9146, 2015.

24. Sun R, Qin C, Jiang B, Fang S, Pan X, Peng L, Liu Z, Li W, Li Y and Li G: Down-regulation of MALAT1 inhibits cervical cancer cell invasion and metastasis by inhibition of epithelial-mesenchymal transition. Mol Biosyst 12: 952-962, 2016.

25. Yang XD, Xu XH, Zhang SY, Wu Y, Xing CG, Ru G, Xu HT and Cao JP: Role of miR-100 in the radioresistance of colorectal cancer cells. Am J Cancer Res 5: 545-559, 2015.

26. Hill L, Browne G and Tulchinsky E: ZEB/miR-200 feedback loop: At the crossroads of signal transduction in cancer. Int $\mathrm{J}$ Cancer 132: 745-754, 2013.

27. Lee WS, Kim N, Park YR, Oh HH, Myung E, Kim SH, Yu HM, Kim MY, Oak CY, Chung CY, et al: Myeloid cell leukemia-1 promotes epithelial-mesenchymal transition of human gastric cancer cells. Oncol Rep 34: 1011-1016, 2015.

28. Drake TM, Ritchie JE, Kanthou C, Staves JJ, Narramore R and Wyld L: Targeting the endoplasmic reticulum mediates radiation sensitivity in colorectal cancer. Exp Mol Pathol 98: 532-539, 2015.

29. Jung J,KimEJ, Chung HK, Park HJ, Jeong SY and Choi EK: c-Myc down-regulation is involved in proteasome inhibitor-mediated enhancement of radiotherapeutic efficacy in non-small cell lung cancer. Int J Oncol 40: 385-390, 2012.

30. Li JY, Li YY, Jin W, Yang Q, Shao ZM and Tian XS: ABT-737 reverses the acquired radioresistance of breast cancer cells by targeting Bcl-2 and Bcl-xL. J Exp Clin Cancer Res 31: 102, 2012. 
31. Chang L, Graham PH, Hao J, Ni J, Bucci J, Cozzi PJ, Kearsley JH and $\mathrm{Li}$ Y: Acquisition of epithelial-mesenchymal transition and cancer stem cell phenotypes is associated with activation of the $\mathrm{PI} 3 \mathrm{~K} / \mathrm{Akt} / \mathrm{mTOR}$ pathway in prostate cancer radioresistance. Cell Death Dis 4: e875, 2013.

32. Ni J, Cozzi P, Hao J, Beretov J, Chang L, Duan W, Shigdar S, Delprado W, Graham P, Bucci J, et al: Epithelial cell adhesion molecule (EpCAM) is associated with prostate cancer metastasis and chemo/radioresistance via the PI3K/Akt/mTOR signaling pathway. Int J Biochem Cell Biol 45: 2736-2748, 2013.

33. Chang L, Graham PH, Hao J, Ni J, Bucci J, Cozzi PJ, Kearsley JH and $\mathrm{Li}$ Y: $\mathrm{PI} 3 \mathrm{~K} / \mathrm{Akt} / \mathrm{mTOR}$ pathway inhibitors enhance radiosensitivity in radioresistant prostate cancer cells through inducing apoptosis, reducing autophagy, suppressing NHEJ and HR repair pathways. Cell Death Dis 5: e1437, 2014.

34. Jing L, Yuan W, Ruofan D, Jinjin Y and Haifeng Q: HOTAIR enhanced aggressive biological behaviors and induced radio-resistance via inhibiting p21 in cervical cancer. Tumour Biol 36: 3611-3619, 2015.

35. Wang G, Li Z, Zhao Q, Zhu Y, Zhao C, Li X, Ma Z, Li X and Zhang Y: LincRNA-p21 enhances the sensitivity of radiotherapy for human colorectal cancer by targeting the Wnt/ $\beta$-catenin signaling pathway. Oncol Rep 31: 1839-1845, 2014.

36. Jiao Y, Liu C, Cui FM, Xu JY, Tong J, Qi XF, Wang LL and Zhu W: Long intergenic non-coding RNA induced by X-ray irradiation regulates DNA damage response signaling in the human bronchial epithelial BEAS-2B cell line. Oncol Lett 9: 169-176, 2015.
37. Lu H, He Y, Lin L, Qi Z, Ma L, Li L and Su Y: Long non-coding RNA MALAT1 modulates radiosensitivity of HR-HPV+ cervical cancer via sponging miR-145. Tumour Biol 37: 1683-1691, 2016.

38. Shinomiya N: New concepts in radiation-induced apoptosis: 'Premitotic apoptosis' and 'postmitotic apoptosis'. J Cell Mol Med 5: 240-253, 2001

39. Jin C, Yan B, Lu Q, Lin Y and Ma L: The role of MALAT1/miR-1/slug axis on radioresistance in nasopharyngeal carcinoma. Tumor Biol 37: 4025-4033, 2016.

40. Yang XD, Xu HT, Xu XH, Ru G, Liu W, Zhu JJ, Wu YY, Zhao K, Wu Y, Xing CG, et al: Knockdown of long non-coding RNA HOTAIR inhibits proliferation and invasiveness and improves radiosensitivity in colorectal cancer. Oncol Rep 35: 479-487, 2016.

41. Pawlik TM and Keyomarsi K: Role of cell cycle in mediating sensitivity to radiotherapy Int J Radiat Oncol Biol Phys 59: 928-942, 2004.

42. Pal I, Dey KK, Chaurasia M, Parida S, Das S, Rajesh Y, Sharma K, Chowdhury T and Mandal M: Cooperative effect of BI-69A11 and celecoxib enhances radiosensitization by modulating DNA damage repair in colon carcinoma. Tumour Biol 37: 6389-6402, 2016.

43. Pádua Alves C, Fonseca AS, Muys BR, de Barros E Lima Bueno R, Bürger MC, de Souza JE, Valente V, Zago MA and Silva WA Jr: Brief report: The lincRNA Hotair is required for epithelial-to-mesenchymal transition and stemness maintenance of cancer cell lines. Stem Cells 31: 2827-2832, 2013. 